\title{
O Ensino, a História e a Lei 10.639
}

Paulo Fernando de Souza Campos ${ }^{I}$

RESUMO

0 debate proposto tem como eixo a Lei 10.639 assinada em janeiro de 2003 pelo Presidente da República Luis Inácio Lula da Silva. 0 texto da normativa altera a Lei n. 9.394, de dezembro de 1996, que estabelece as diretrizes e bases da educação nacional, por incluir no currículo oficial da Rede de Ensino a obrigatoriedade da temática História e Cultura Afro-Brasileira nos estabelecimentos de ensino fundamental e médio, oficiais e particulares. Pretende-se uma reflexão acerca das condicionantes que levaram à promulgação da referida lei e as vicissitudes das mudanças propostas sobretudo no processo ensino-aprendizagem.

Palavras-chave: ensino de história, história e cultura afro-brasileira, Lei 10.639

O conteúdo referente à inclusão dos tópicos de História da África e dos africanos, da experiência e cultura negra brasileira, bem como a contribuição dos povos africanos e afro-brasileiros nas áreas social, econômica e política pertinentes à História do Brasil na formação básica integra um longo e denso debate acerca da marginalização dos negros na sociedade brasileira.

As proposições da Lei 10.639 exigem revisões não apenas das interpretações da trajetória histórica dos negros africanos e afro-brasileiros, até então representada pela via quase exclusiva da desigualdade e intolerância, geradora de inversões do significado de ser negro no Brasil mas das práticas de ensino nas áreas de Educação Artística, Literatura e História exigindo uma mudança radical das tradicionais abordagens didático-pedagógicas em relação aos problemas colocados pelos tópicos de cultura africana, diáspora negra, representações do trabalho escravo, entre outros. 0 que se observa é uma busca pelo desmonte de imagens e discursos construídos ao longo da História do Brasil que impuseram aos negros uma condição de inferioridade na formação sócio-educacional brasileira.

${ }^{1}$ Professor das Faculdades Integradas Eistein - FIEL -Limeira - SP. 
De acordo com os últimos dados censitários, apenas 6,8\% da população brasileira com mais de 25 anos possuem nivel superior completo. Desse percentual, 82,8\% são brancos. Em relação ao ensino fundamental, $63,2 \%$ dos brasileiros maiores de 25 anos não concluíram a oitava série, o que representa um índice alarmante se pensado em termos da marginalização dos negros na formação sócio-educacional pois, apenas $2,1 \%$ dos mais de $40 \%$ de negros que compõe a população nacional possuem nível superior completo: reflexo direto da exclusão educacional sofrida pelos negros na trajetória histórico-educacional do Brasil.

Com a publicação da Lei 10.639, as abordagens do fazer histórico e das culturas africanas visam ao desenvolvimento crítico das origens e experiências dos negros negando reducionismos pautados em juízos de valor, construções discursivas e outras estratégias do poder resultantes de codificações, produções imagéticas e verdades institucionalmente aceitas, perenizadas, inclusive, no âmbito escolar. Tais vicissitudes moldaram mentalidades, práticas e representações assumidas como naturais, como a idéia que implica supor que ser negro no Brasil corresponde a ser escravo, sem se dar conta que a escravidão é um fenômeno anterior ou que ser negro é sinônimo de inferioridade, naturalizando, assim, diferenças e ambiguiidades, fator eiementar da formação do mito da democracia racial no Brasil.

Todavia, ainda que provocadora de mudanças, as proposituras da nova lei conduzem a questionamentos que merecem muita atenção por parte dos educadores pois, como ministrar aulas sobre a História da África e das culturas africanas se a imensa maioria dos cursos de Licenciatura do país não contemplam a matéria? Como debater o tema em sala de aula para uma sociedade que ainda não assumiu seus preconceitos e idiossincrasias? Como abordar temáticas da história africana e cultura afro-brasileira se os livros didáticos, ná maioria das vezes, perenizaram imagens que corroboram a inferiorização dos negros, limitando o conhecimento em torno de suas experiências ao apresentá-las a partir da violência, da indolência, do castigo, da fuga e demais elementos característicos da submissão dos corpos?

Movido pela nova lei, o debate sobre o tema tem se apresentado recorrente em cursos de licenciatura, em específico nas áreas da História, Literatura e Educação 
Artística na medida em que poucos são os profissionais dedicados ao estudo do continente africano e diáspora negra, assim como é diminuta a circulação da produção bibliográfica sobre os temas e autores africanos entre a maioria dos alunos de graduação e pós-graduação do Brasil, país de imensos alcances geográficos cujo ambiente escolar, degradado pela inoperância que desvaloniza a experiência do aluno em favor de um sistema educacional quantitativo e não qualitativo, continua a fabricar uma educação unilateral, pautada no bio-poder fundador de umá pedagogia eugênica que calcificou o sistema educacional como algo limitador, hierarquizado, avesso ao espírito crítico.

Contudo, a nova produção acadêmica tem disseminando conteúdos que questionam os arcaísmos de imagens constantemente desfocadas em relação à cultura e história afro-brasileira. 0 discurso fossilizado da democracia racial, a reprodução de imagens dilacerantes e repletas de estereótipos que remontam o Brasil Colônia, Império e República Velha expõe a história dos negros pela via da inferioridade nata, corroborando construções discursivas e imagéticas que evidenciavam os negros por um lado como "crias da casa", boçais, domesticalizados e por outro lado, acentuadamente evolucionista, como degenerados, criminosos natos, corrompidos física e moralmente (SANTOS, 2002; SOUZA CAMPOS, 2003).

Assim, refletir sobre o assunto implica compreender que as experiências dos negros africanos e afro-brasileiros não se resumem a episódios trágicos, tramas ilegais, vivências indistintas ou comportamentos desviantes com os quais foram constantemente identificados. Para tanto, é preciso re-significar atuações do movimento e experiências afro-brasileiras que, no âmbito do ensino formal, ainda são estudadas a partir do desvio, interpretadas por uma perspectiva unilateral que direciona o olhar e impõe aos negros uma permanência marginal na história, como páreas da sociedade - mesmo que imageticamente, mesmo que tais imagens não correspondam com o real.

O saber pedagógico como dispositivo higiênico e moralizador

A história da educação no Brasil permite afirmar que nas primeiras décadas do século XX os critérios raciais operavam distinguindo a população em educáveis, portanto, capazes da cidadania e populações em que o peso da hereditariedade, 
pensado em termos raciais, refletia a marca de um destino que a educação era incapaz de alterar. O saber pedagógico republicano considerado moderno, experimental e científico, configurou a educação formal como campo de intervenções disciplinares cujas determinações estabeleciam a quem caberia estudar e o seu contrário. Os negros, nessa perspectiva, eram invariavelmente excluídos da escola sof́rendo ai uma tripla marginalidade: pretos, pobres e analfabetos.

O saber pedagógico atuou nas origens da República como um grande veículo disseminador das propostas higienizadoras e classificatórias de pessoas, associando pobres a personagens perigosos e negros a criminosos natos, incivilizados e incapazes: daí a idéia de que nem mesmo a educação poderia alterar as mazelas da degeneração imputada aos negros que, nessa medida, foram compelidos a viver à margem da sociedade do trabalho urbano - sem, contudo, eximirem-se das lutas, negociações e conflitos que as representações da desigualdade e inferioridade nata impunham como verdades (MARQUES, 1994).

A escola operava como o centro irradiador de práticas moralizadoras e disciplinares no sentido do melhoramento do indivíduo e da "espécie". Conforme salienta Marta Maria Chagas de CARVALHO o ambiente escolar, durante muito tempo, foi o espaço disseminador de uma noção eugênica que distinguia culturas e excluía pessoas, "...discriminar as crianças normais das anormais ou degeneradas era tarefa que se instalava no âmago da pedagogia científica [...] Para tanto, importava não confundir " os casos de anomalia simples com os de grave e profunda degeneração"'. Prosseguindo em sua análise crítica da documentação utilizada, a autora acrescenta: "...os primeiros podem 'ser compatíveis com a natureza e fim da escola', sendo-lhes facultado 'frequientar as escolas dos normais', onde 'seriam corrigidos e modificados por métodos especiais'. Já 'os degenerados' devem ser 'excluídos absolutamente das escolas dos normais, seja qual for a forma de seu caráter degenerativo'..." (1997, p. 298).

Em entrevista recente, Décio SAES (2003) afirmou que ainda hoje a escola pública ministra um ensino de classe média que condena os filhos da classe trabalhadora ao fracasso. De acordo com o autor, o sistema de ensino público não aproveita a inclinação das crianças pobres ou suas atividades

1 As expressões em destaque reproduzem um dos documentos utilizados pela autora para fundamentar as inierpretaçõos sobre as modalidades de constituição da infäncia como objeto de intervenção disciplinar, higiênica as quais, vale destacar, reportam os escritos de Oscar THOMPSON (1914). 
tratando tudo de modo elitista, teoricista e abstrato, além de imprimir a idéia de que há oportunidades iguais para pessoas diferentes; o que não existe efetivamente na vida das pessoas, sobretudo na vida de grande parte de afrobrasileiros, ou melhor, dos brasileiros.

Diante desse quadro não há como negar a importância histórica da đecisão efetivada pela Lei 10.639 e da ação afirmativa que ela pretende. Porém, tal processo pressupõe o reconhecimento de uma nova mentalidade a ser contemplada sobretudo pelos profissionais da educação. Promover a preservação dos valores sociais, culturais e econômicos decorrentes da influência africana na formação da sociedade brasileira oferece ao trabalho do educador uma rica possibilidade para repensar sua própria função e importância social. Tratando especificamente do ensino de História, tal promoção permite reconhecer a importância capital do Professor de História no processo da mudança. Para tanto, é preciso combater o racismo e a intolerância que existe nas expressões do cotidiano diagnosticando-as, decisivamente, no ambiente escolar, na sala de aula, na vivência de alunos e educadores no processo ensino-aprendizagem, na noção que se tem de escola e de práticas pedagógicas.

\section{A Lei 10.639 como um marco para a mudança}

0 conhecimento das culturas africanas tradicionais, das mitologias africanas, o aprendizado das religiões afro-brasileiras, dos conflitos, das tensões e demandas de homens e mulheres negros possibilitará re-significar sociabilidades, acontecimentos, negociações e contradições capazes de promover uma outra representação e conhecimento da sociedade brasileira, propiciando o desmonte de leituras e memórias que perenizam a discriminação e conduzem aos segregacionismos.

A Lei 10.639 permite que a gravíssima questão da desigualdade educacional no Brasil possa ser reavaliada, especialmente porque o campo educacional influi poderosamente nas perspectivas futuras de participação social e de acesso às posições melhor remuneradas no mercado de trabalho. Os dados referentes à população adulta brasileira demonstram que 12,9\% de brancos completam o ensino médio, enquanto apenas 3,3\% dos negros possuem 0 mesmo diploma. De acordo com o Mapa da Exclusão Educacional, resultado 
do estudo do Instituto Nacional de Estudos e Pesquisas Educacionais - Inep feito a partir dos dados do IBGE e do Censo Educacional do Ministério da Educação - MEC, 1,4 milhão de crianças, o equivalente a 5,5\% da população entre 7 a 14 anos, não frequientam o ensino básico, o que permite afirmar que a frequiência à escola no Brasil ainda é um privilégio. No Estado do Paraná, $4,4 \%$ das crianças nessa faixa de idade estão fora da escola, resultando no pior índice da região sul na medida em que o mesmo índice em Santa Catarina cai para 3,4\% e 2,7\% no Rio Grande do Sul.

Nesses termos, vale destacar ainda que apenas $11,3 \%$ dos alunos da quarta série do ensino fundamental se declararam negros. Segundo os dados do Sistema Nacional de Avaliação da Educação Básica - Saeb de 2001, quando os adolescentes negros chegam à oitava série, o percentual cai para 8\% e que somente $6,4 \%$ dos alunos que concluíram o terceiro ano do ensino médio se declararam negros.

Na passagem para o século XXI, a secretária de Estado da Educação de São Paulo Rose NEUBAUER (2000), ao comentar os resultados do Sistema de Avaliação do Ensino Básico - Saeb do Ministério da Educação - MEC de 1999 afirmou que a escola pública não se preparou para receber alunos carentes, afirmação no mínimo paradoxal na medida em que a escola pública deveria cumprir exatamente o contrário, vale dizer, receber e formar com qualidade crianças e adolescentes oriundos das classes menos favorecidas da sociedade.

Os argumentos sobre a verificação da queda na qualidade do ensino básico afirmam que o decréscimo aconteceu pois "...essa é a população que tem menos contato com comportamentos acadêmicos, que tem menos livros em casa, menos acesso à leitura, menos contato com o teatro, cinema e outras características que influem no rendimento escolar..." (IDEM, p. 7). Como resposta aos problemas evidenciados pela avaliação do Saeb, a secretária do Estado da Educação de São Paulo reiterou dizendo que para aumentar a qualidade do ensino fundamental e médio a escola precisa estar "...mais bem aparelhada...". Porém, aparelhar a escola dotando-a de recursos técnicos será suficiente para alterar a queda na qualidade do ensino público? A adoção de práticas interativas e metodologias que servem para tornar o aprendizado mais prazeroso resolverá os problemas?

Melhorar a qualidade do ensino no Brasil exige, muito mais do que 
recursos técnicos, a mudança nas formas do olhar, dos atributos utilizados na decodificação do visível os quais, por sua vez, possibilitam a (des)construção da imagem do outro. Paula POGRÉ (apud CAMARGO, 2004), indica que muitas escolas costumam inovar nas estratégias sem contudo alcançar o resultado esperado, qual seja, o aprendizado, afirmando que "...teatro é teatro, história é história. Pode ser inútil pular de uma área para outra, sem ter clareza dos objetivos, dos critérios e do que se quer demonstrar [...] nem sempre aprender é gostoso" (IDEM, p. 16).

O diferencial, nestes termos, exige a formação de práticas de ensino singulares a uma pedagogia cidadã capaz de provocar a compreensão por parte dos educadores da necessária recuperação das deformações que limitam o horizonte cultural da formação sócio-educacional brasileira compensando o processo cumulativo da desigualdade pois, dado o caráter tradicionalmente excludente da escola brasileira, a educação munca foi um canal acessível de mobilidade social mas, muito mais, de reprodução de valores diametralmente opostos aos propostos pela Lei 10.639, quais sejam, exclusões e formação de intolerâncias.

De acordo com Irene Sales de SOUZA, os mecanismos discriminatórios afetam o aluno negro no sistema educacional em termos organizacionais, curriculares e de socialização. Em suas constatações, as crianças negras repetem mais de ano e tendem a ser "empurradas" para escolas menos equipadas, freqüientando os piores cursos que são, em sua maioria, ministrados por profissionais mal formados ou desgastados pela espoliação e desvalorização de seu ofício. Para a autora, a escola reafirma o racismo. "... A percepção que os professores têm desses alunos é que são filhos de pais bêbados, desempregados, de famílias incompletas, que os meninos não tem higiene, não prestam atenção, etc. Muitos componentes dessa profecia se realizam, mesmo quando a criança não se apresenta como tal" (2001, p.13)

Entretanto, a escola é o lugar por excelência do desmonte das fabricações que reduzem a população afro-brasileira e pobre à idéia de uma inoperância desclassificatória, fruto de uma representação contraproducente forjada para controlar o que caracteriza o povo brasileiro, qual seja, a sua identidade plural, miscigenada. Tomar consciência de que o ambiente escolar favoreceu - e tem continuamente favorecido - à auto-depreciação, à construção de uma anti-imagem e de sentimentos negativos impostos pelo racismo é o primeiro passo à construção de uma prática 
pedagógica inclusiva, poderosa, que represente as inquietudes e não os acomodamentos do principal agente que atua no ambiente escolar: os alunos.

Por um outro ensino e por uma outra escola

0 ambiente escolar brasileiro apresenta inúmeros problemas. Um deles, talvez o mais grave, diz respeito a sua organização e estrutura curricular. Voltada para as disciplinas das chamadas ciências exatas e da terra como a biologia, a física e a química, a escola perdeu sua dimensão humanitária deslocando disciplinas correlatas às humanidades a uma escala reduzida tanto em relação às cargas-horárias dedicadas ao estudo dos saberes nos quais se inserem quanto em termos da importância das mesmas na formação da criança e do adolescente. No caso específico da História, é notório que a disciplina, no Brasil, foi relegada aos tradicionalismos de uma cultura fossilizada, pautada no vazio das datas comemorativas, dos mitos fundadores, dos vultos heróicos, reduzindo o potencial da matéria que, grosso modo, implica no trabalho com as noções de tempo e espaço, base para uma pedagogia da compreensão.

Em recente publicação, Cíntia CARDOSO (2004) apresenta um modelo de escola que, guardada as devidas proporções, tem o ensino de História como base curricular e plataforma para produção do conhecimento. Trata-se da Ross School em East Hampton, cidade litorânea dos EUA, um balneário sofisticado a $160 \mathrm{Km}$ de Nova York. Nessa "escola de luxo", 50\% dos 276 alunos recebem Bolsas de estudo cujos critérios de seleção não passam pelo desempenho escolar, por suas proverbiais genialidades, pela moralidade e condição de suas famílias, buscando ai um perfil desejável mas pela diversidade e interesses variados contrários à tipificação das pessoas.

Assumindo a História como base curricular, todas as demais disciplinas - matemática, ciências (física, química), biologia e ciência ambiental, inglês, línguas estrangeiras (latim, francês, espanhol e chinês), artes, mídia e tecnologia - se cruzam. "...0 currículo forma uma espiral em que cada série corresponde a um período da história da humanidade [...] Todas as disciplinas usam fatos relacionados aos períodos históricos determinados como pano de fundo para as aulas..." (IDEM, p. 18)

Mesmo que difícil de ser imaginado em um país como o Brasil, cuja 
imensa maioria dos empresários da educação identificam seus alunos como meros clientes, nivelando o ensino a um produto cujo referente maior são os lucros e não o aprendizado, o exemplo se destaca pela evidencia da História enquanto disciplina norteadora do que se concebeu como uma prática pedagógica formadora de "... alunos que interajam com a sociedade, e não uma massa para linha de montagem..." como pensam muitos que detém o poder político de gerir os destinos da escola no Brasil (IBIDEM, p. 19).

Para o caso brasileiro, a questão da qualidade do ensino e da construção de uma outra escola também passa pela elitização dos campos de atuação profissional. A vaidade acadêmica que segrega os que não lecionam no ensino universitário on em escolas de ensino fundamental e médio para ricos erigiu barreiras que fissuraram um dos eixos que dá sentido à própria instituição universitária, isto é, a extensão. Poucos são os projetos que tendem a estreitar o diálogo entre os diferentes níveis da atuação profissional de educadores ou que promovam a transformaçấo da realidade educacional brasileira.

Significativos, nestes termos, são os resultados apontados no estudo divulgado pelo Ministério da Educação - MEC intitulado Estatísticas dos Professores no Brasil os quais revelaram que apenas $57 \%$ dos docentes que atuavam no período de 1996 a 2002 na pré-escola, no ensino fundamental e médio possuíam formação em nível superior e que dos cerca de 2,4 milhões de professores da educação básica, $80 \%$ atuavam na escola pública. Nessa perspectiva, de acordo com estudo realizado pelo Instituto Nacional de Estudos e Pesquisas Educacionais - Inep, dos professores que atuavam em 2002 nas primeiras quatro séries do ensino fundamental, apenas 26,4\% possuíam formação superior, índices que permitem dimensionar os abismos entre a universidade e a prática pedagógica nas escolas, entre o conhecimento prodızido nos centros de estudos superiores e o conhecimento pessoal e prático do professor de ensino fundamental e médio, especificamente os que atuam na escola pública, vale reiterar, quase a totalidade.

Nas fronteiras do (im)provável?

A promulgação da Lei 10.639 , nesse sentido, possibilita a emancipação da prática educacional e a valorização dos conteúdos de História. De maneira geral, a inclusão dos tópicos de História e Cultura Afro-Brasileira no ensino 
básico é uma chance a mais no processo de decodificação da sociedade brasileira pois, ao retirar das sombras uma cultura e população nodal à compreensão do ser brasileiro, o estudo das temáticas em relevo propicia a re-significação de acontecimentos, períodos históricos e relações sociais que, no jogo das escalas da análise, favorece a produção de outros sentidos, contribui à produção de outras representações de si mesmo, desmontando discursos, auto-percepções e políticas públicas que visavam ao controle da sociedade tanto ao nível das idéias, quanto ao nível da práxis (CARNEIRO, 1996).

Mesmo que alguns índices apontem para uma real inclusão das "minorias" é ainda preciso lembrar que os números sangram. Não basta creditar às cifras de estudos estatísticos a prova de uma extraordinária mobilidade, evidencia que desmonta a idéia da incapacidade. Localizados em grandes centros urbanos, voltados para cursos noturnos cuja concorrência é diminuta e o mercado de trabalho exíguo, como é o caso dos Cursos de História, tais estatísticas representam uma realidade em curso e não o efeito real da mudança, sobretudo para os que já venceram a etapa do ensino fundamental e médio. No Brasil, a questão do mérito (FLORENTINO, 2004), cabe ressaltar, é sufocada pela violência do olhar que discrimina, segrega e que torna a desigualdade algo natural, em específico para os que vivem o momento atual - na medida em que os que virão já despontam como incluídos na realidade da mudança.

Como toda tomada de decisão, os dispositivos da lei em causa apontam para outras problemáticas como as referentes aos cursos de capacitação e a redução do conteúdo programático anual das disciplinas História do Brasil e Educação Artística no ensino médio em dez por cento à temática História e Cultura Afro-Brasileira. Assim, a Lei 10.639 indica outros contomos que conduzem a novos debates, contudo, a promulgação da normativa em relevo permite refazer o percurso, repensar 0 ensino indagando sobre em que consiste o conhecimento e como ele pode ser legitimado remetendo, desse modo, o debate a diferentes problemáticas como, por exemplo, sobre o conjunto de estratégias que interferem na produção do conhecimento e na base da relação ensino-aprendizagem.

Refazer o percurso, nessa medida, implica na transformação da ética e dos valores morais acionados pelo bio-poder médico, dos interesses pessoais ou corporativos, das convicções avessas ao espírito crítico, reconhecendo o que a História mesma já revelou como inoperante, dogmático, fabricado por uma leitura de mundo que não existe mais. 
Agradecimentos

As idéias abordadas não seriam possiveis sem a colaboração da Professora Helany Morbin que aceitou participar da composição da Comunicação Coordenada que sistematizou as reflexões em pauta. Da mesma forma, agradeço ao Núcleo Negro da UNESP para Pesquisa e Extensão - NUPE, em especial a Profa. Dra. Tânia Macedo. Não poderia deixar de agradecer a Alessandra Rosa Carrijo cujo apoio incondicional tem permitido diferentes alcances nesses tempos difíceis.

Bibliografia

BERGAMO, Mônica. Retratos do Brasil. Ensino fundamental não atinge 1,4 milhão. Folha de S'. Paulo, São Paulo, 3 dez. 2003. Folha Cotidiano, Caderno C, p. 3.

BRASIL. Lei ñ ${ }^{\circ}$.10.639, de 9 de janeiro de 2003. Altera a legislação que estabelece as diretrizes e bases da educação nacional. Diário Oficial [da] República Federativa do Brasil, Brasília, DF, 10 jan. 2003. Disponível em: <http://www.senado.gov.br>. Acesso em: 30 set. 2003.

CAMARGO, Paulo de. Quando o problema não é o aluno. Folha de S. Paulo, São Paulo, 27 jan. 2004. Folha Sinapse, p. 14-16.

CARDOSO, Cíntia. Um modelo de luxo. Alunos de escola de elite nos EUA circulam de pantufas entre obras de arte e aprendem história em viagens internacionais. Folha de S. Paulo, São Paulo, 27 jan. 2004. Folha Sinapse, p.18-19.

CARNEIRo, Maria Luiza Tucci. o discurso da intolerância. Fontes para o estudo do racismo In: Di CREDDO, Maria do Carmo Sampaio (Coord.) Fontes Históricas: abordagens e métodos. Assis: Programa de Pćs-Graduação em História, 1996. p. 21-32.

CARVALHO, Marta Maria Chagas de. Quando a história da educação é a história da disciplina e da higienização das pessoas In: FRETTAS, Marcos Cezar de. (Org.) História social da infância no Brasil. 3ed. São Paulo/Bràgança Paulista: Cortez/USF, 2001. p. 291-310.

CONSTANTINO, Luciana. Ensino. Professor estuda mais, mas salário é baixo. Folba de s. Paulo, São Paulo, 16 out. 2003. Folha Cotidiano, Caderno C, p. 6.

ESCósSia, Fernanda da. Retratos do Brasil. Só 5,8 milhões tem curso superior no Brasil. Folha de S. Paulo, São Paulo, 3 dez. 2003. Folha Cotidiano, p. 1.

FlorentTino, Manolo. o ministro da Educação sabe. Folha de S. Paulo, São Paulo, 4 fev. 2004. Brasil, Caderno A, p. 3. Tendências e Debates. 
MARQUUS, Vera Regina Beltrão. A medicalizaçâo da raça. Médicos, educadores e discurso eugênico. Campinas: Editora da UNICAMP, 1994.

NEUBAUER, Rose. Escola pública não se preparou para receber carente. Folba de S. Paulo, São Paulo, 27 nov. 2000. Brasil, Caderno A, p. 7. Entrevista concedida a Antonio Gois.

SAES, D. Escola 'condena' crianças pobres, afirma cientista. Folba de S. Paulo, São Paulo, 15 jul. 2003. Entrevista concedida a Guilherme Bahia.

SANTOS, Gislene A. dos. A invenção do ser negro - Um percurso das idéias naturalizaram a inferioridade dos negros. São Paulo/Rio de Janeiro: EDUC/Pallas/Fapesp, 2002.

SOUZA CAMPOS, Paulo Fernando de. Os crimes de preto Amaral. Representações da degenerescência em São Paulo. 1920. Assis, 2003. 325 p. Tese (Doutorado em Fistória) Faculdade de Ciências e Letras - Universidade Estadual Paulista "Júlio de Mesquita Filho".

SOUZA, Irene Sales de. Os educadores e as relações interétnicas: pais e mestres. Franca: UNESP-FHDSS, 2001.

THOMPSON, Oscar. 0 futuro da pedagogia é científico. In: Laboratório de Pedagogia Experimental, São Paulo, Tip. Siqueira, Nagel \& Comp., 1914, p. 17 e 18.

\section{The teaching, the History and the Law 10.639}

\section{ABSTRACT}

The proposed debate has as axis the Law 10.639 signed in January of 2003 by Brazilian President Luis Inácio Lula da Silva. The text of the normative alters the Law n. 9.394, of December of 1996, that it establishes the guidelines and bases of the national education, for including in the official curriculum of the Net of Teaching the compulsory nature of the theme History and Afro-Brazilian Culture in the fundamental and secondary education officials and privates. A reflection is intended concerning the imposes that promulgation of the referred law and the transformation of the changes proposed above all in the process teaching-learning.

Key words: history teaching, history and afro-brazilian culture, law 10.639 